\title{
Perfil psicológico de prestação dos atletas paralímpicos Atenas 2004
}

Ana Rita Bodas, João Paulo Lázaro, Hélder Miguel Fernandes

FCT - Centro de Estudos em Educação e Psicologia da Universidade

de Trás-os-Montes e Alto Douro (Portugal)

Bodas, A.; Lázaro, J; Fernandes, H; Perfil psicológico de prestação dos atletas paralímpicos Atenas 2004. Motricidade 3(3): 33-43

\section{Resumo}

A compreensão e determinação das componentes psicológicas geradoras de diferenças de rendimento nos momentos de competição, revela-se fundamental para o desenvolvimento de intervenções adequadas ao nível do treino desportivo. O presente estudo centrou-se na determinação das características psicológicas que definem os atletas paralímpicos, com base nos parâmetros do Perfil Psicológico de Prestação. A amostra foi constituída por 28 atletas (21 homens e 7 mulheres) de quatro modalidades e três tipos de deficiência, com idades compreendidas entre os 19 e os 49 anos $(M=31.14, \mathrm{SD}=6.69)$, que representam a totalidade dos atletas seleccionados para os Jogos Paralímpicos de Atenas 2004 sem afectação cognitiva. O questionário utilizado foi o do Perfil Psicológico de Prestação, que considera a avaliação de sete variáveis psicológicas: (i) autoconfiança, (ii) pensamentos negativos, (iii) pensamentos positivos, (iv) atenção, (v) visualização, (vi) motivação e (vii) atitude competitiva. Os procedimentos estatísticos consistiram em análise descritiva, análise correlativa e análise comparativa, para um nível de significância de 0.05 . Os principais resultados indicaram níveis elevados de preparação psicológica, sistemática para as variáveis motivação $(27.43+1.99)$, autoconfiança $(27.18+2.57)$ e atitude competitiva $(25.61+2.68)$, e não sistemática para o positivismo $(24.86+2.53)$, visualização $(23.29+4.02)$, atenção $(23,07+3,36)$ e negativismo $(21.11+3.19)$. Evidenciaram-se ainda diferenças significativas entre os atletas de acordo com o tipo de deficiência, modalidade e títulos conquistados.

Palavras-chave: variáveis do Perfil Psicológico de Prestação, atletas paralímpicos.

\section{Abstract \\ Psychological profile of paralympics athletes in Athens 2004}

The identification and comprehension of the psychological components which determine the differences between the high performance athletes at competition time, is absolutely necessary in order to choose the suitable interventions when coaching. The present study describes the identification of the psychological profiles that distinguish the athletes of different sport modalities and different disabilities, based on the Psychological Performance Profile. The sample concerns 28 athletes (21 men and 7 women) from four sport modalities and three different kinds of disability. The age of the athletes ranged from 19 and 49 years old $(M=31.14$, $\mathrm{SD}=6.69)$, which represent the total athletes selected for the Athens 2004 Paralympic Games, without any cognitive problems. The inventory used was that of the Psychological Performance Profile, who takes into consideration the evaluation of seven psychological variables: self-confidence, negativism, positivism, attention, visualization, motivation and attitude control. The statistical procedures were based on descriptive, correlative and comparative analysis, with a significance level of 0.05 . The main results showed high level of psychological preparation, regular for the variables: motivation $(27.43+1.99)$, self-confidence $(27.18+2.57)$ and attitude control $(25.61+2.68)$, and non-regular for positivism $(24.86+2.53)$, visualization $(23.29+4.02)$, attention $(23,07+3,36)$ and negativism $(21.11+3.19)$. This study also found statistically important differences between paralympic athletes according to the kind of handicap, sportive modality and ranks.

Key words: Psychological Performance Profile variables, paralympic athletes. 


\section{Introdução}

A compreensão do efeito dos factores psicológicos no comportamento humano em contextos desportivos e dos efeitos psicológicos que a participação no desporto ou na actividade física poderão ter nos participantes, tem vindo a caracterizar o âmbito de estudo da Psicologia do Desporto ${ }^{1}$, pelo que a maior parte da pesquisa neste domínio tem apresentado dois objectivos centrais: (i) compreender de que forma os factores psicológicos afectam o rendimento desportivo dos indivíduos; e (ii) como é que a participação no desporto e no exercício afecta o desenvolvimento psicológico, a saúde e o bem-estar desses mesmos indivíduos ${ }^{18}$.

Pensamos então ser cada vez mais fundamental uma abordagem multidisciplinar ao treino e à competição. Num momento desportivo como o actual, em que as diferenças patentes entre os atletas são cada vez mais reduzidas ao nível da preparação física, capacidade técnica e compreensão e inteligência tácticas, a procura de novos elementos como são as competências psicológicas, revelam-se decisivas na busca de resultados. Isto acontece particularmente ao nível Olímpico, em que a diferença entre ganhar e perder dista frequentemente escassos milésimos ou milímetros. Sob estas condições, o sucesso está frequentemente dependente da capacidade do indivíduo para controlar os factores psicológicos inerentes à performance, e assim competir ao seu melhor nível, potencializando e explorando ao máximo as suas capacidades.

Uma preparação psicológica adequada e sistemática revela-se decisiva para suprir uma falha, uma lacuna existente entre o que se é capaz de fazer enquanto atleta e aquilo que realmente se faz durante uma prestação: a lacuna entre o potencial e a realização desse potencial ${ }^{7}$.

Para Vasconcelos-Raposo ${ }^{14}$ o desenvolvimento da excelência depende directamente das atitudes face às exigências impostas pelo treino e competição. Assim, podemos não ser capazes de controlar todas as situações em competição, mas se controlarmos a nossa resposta a essas situações, estaremos a influir decisivamente na nossa performance, e no nosso controlo final sobre a mesma. 'I can't control the wind, but I can control my emotional reaction to the wind, and when I do, in a sense, I control the wind"'.

O Desporto Adaptado tem registado uma evolução acentuada no plano puramente desportivo, sendo que esta pressão de desenvolvimento desencadeia maiores exigências no plano da preparação dos atletas, quer para o treino, quer para a competição. Se por um lado, os técnicos têm sentido grande necessidade em ter acesso a informações específicas que possam apoiar o seu trabalho nas diferentes modalidades, sendo essas raras, não acessíveis e dispersas (facto que contribui para o empirismo latente na intervenção técnica dos treinadores, e assim para algumas dificuldades evidenciadas na preparação dos atletas); por outro, parece-nos ser fundamental uma procura de informação na área das componentes mentais do treino, na medida em que estas possibilitam um melhor entendimento dos processos e respostas psicológicas (o que pode ser particularmente positivo neste tipo de atletas), e podem constituir uma mais valia, não apenas no Desporto Adaptado, mas no desenvolvimento desportivo em geral.

A capacidade de alcançar níveis desejados e consistentes de performance em competição, está naturalmente associada ao grau de preparação do atleta, mas estará sobretudo dependente da forma como essa preparação se coaduna com as exigências específicas da competição, pelo que o desenvolvimento das competências psicológicas deverá ser orientado de acordo com essas mesmas exigências, que se revelam distintas de acordo com características particulares das diferentes modalidades.

Entre as diversas modalidades, o boccia é um desporto algo peculiar que se distingue dos restantes pelo facto de solicitar um reduzido 
envolvimento muscular e energético, apresentando os atletas baixa condição física, mas em que a fadiga parece aparecer com alguma frequência, evidenciando-se fundamentalmente ao nível dos processos de concentração'. A uma reduzida intensidade de esforço opõe-se a necessidade de uma elevada capacidade atencional, decorrente das exigências ao nível do controlo psicomotor, em especial da coordenação óculo-motora (grande precisão de acções), situação onde um adequado treino de visualização mental se pode revelar determinante. É um jogo de grande teor técnico e táctico, que exige forte capacidade estratégica, e assim elevados níveis de autoconfiança na tomada de decisões durante toda a prova. As suas características ao nível de duração e da existência de tempos de pausa intermédios durante a prova, exigem um elevado controlo emocional e uma preparação mental capaz de neutralizar ao máximo a ocorrência de pensamentos negativos. Igualmente, a presença do público pode influir decisivamente neste aspecto, se considerarmos a necessidade de demonstração de competência destes atletas perante um "conjunto de olhares" capazes de percepcionar e avaliar as suas evidentes limitações físicas, situação capaz de influir no auto-conceito dos atletas no caso de uma prestação menos bem sucedida. Deste modo, verifica-se uma elevada exigência ao nível psicológico durante toda a prova, em que a acção do atleta está frequentemente condicionada pela acção adversária.

No que respeita à natação e ao atletismo, verificam-se outras situações passíveis de alterar os seus estados emocionais e psicológicos. Em ambas as modalidades constatamos uma predominância da capacidade técnica relativamente à táctica, e uma elevada intensidade de esforço, que exige fundamentalmente ao nível da condição física dos atletas. Os factores psicológicos manifestam-se essencialmente antes do início da competição, visto serem provas na sua maioria rápidas, e em que a prestação do atleta não está condicionada pela acção adversária (o resultado ocorre em função do tempo de prova). A sua duração influi ainda na percepção de factores externos, como a presença do público, pelo que neste parâmetro estas modalidades parecem ser menos ameaçadoras para o auto-conceito e autoconfiança dos indivíduos, comparativamente ao boccia. O facto de as limitações físicas serem também menos evidentes, especialmente no caso do atletismo (praticado por cegos) pode também contribuir para essa questão. Já no que concerne à natação, esta parece possuir elevadas exigências em termos emocionais, visto ser praticada num meio com características particulares, em que os handicaps físicos constituem um acréscimo importante às dificuldades sentidas.

Pelo exposto, o propósito deste estudo foi identificar o nível de preparação dos atletas nas diferentes componentes psicológicas do treino, por forma a caracterizar um perfil de prestação da elite do Desporto Adaptado nacional, que possa contribuir com dados concretos e práticos (e não apenas suposições teóricas), susceptíveis de promover uma área de intervenção válida e determinante no treino dos atletas de alto nível, e assim potenciar performances futuras como sejam próximas participações paralímpicas.

\section{Metodologia Amostra}

A amostra foi constituída por 28 indivíduos (21 homens e 7 mulheres), com idades compreendidas entre os 19 e os 49 anos $(M=31.14$, $\mathrm{SD}=6.69)$, de 4 modalidades distintas, representando 3 associações nacionais (ACAPO, ANDDEMOT e PCAND). Somente fizeram parte da amostra 28 atletas dos 41 que formaram a comitiva Paralímpica Portuguesa, pelo facto de os restantes 13 atletas possuírem défice 
cognitivo. No quadro 1 e 2 é feita a sua caracterização sistémica e de acordo com algumas variáveis em estudo. Os procedimentos utilizados respeitam as normas internacionais de experimentação com humanos (Declaração de Helsínquia de 1975).

\section{Procedimentos}

$\mathrm{Na}$ realização do presente estudo, utilizámos o questionário do Perfil Psicológico de Prestação (PPP), originalmente desenvolvido por Loher
(1986) e traduzido e validado para português por Vasconcelos-Raposo (1993). Este teste é constituído por 42 questões que visam avaliar 7 variáveis psicológicas de prestação: autoconfiança, pensamentos negativos, pensamentos positivos, atenção, visualização, motivação e atitude competitiva. Para cada uma das questões existem 5 possibilidades de resposta fechada numa escala tipo Likert: quase sempre, frequentemente, às vezes, raramente e quase nunca. Os valores deste teste oscilam entre 0 e 30 , identificando três níveis de preparação psicológica dentro deste

Quadro 1: Caracterização sistemática da amostra.

\section{Número de sujeitos}

$n=28$

\begin{tabular}{|c|c|c|c|c|}
\hline \multirow{2}{*}{$\begin{array}{l}\text { Sexo } \\
\text { Idade }\end{array}$} & \multicolumn{2}{|c|}{$\begin{array}{c}\text { MASCULINO } \\
\mathrm{n}=21 \text { (75.0\%) }\end{array}$} & \multicolumn{2}{|c|}{$\begin{array}{c}\text { FEMININO } \\
\mathrm{n}=7 \text { (25.0\%) }\end{array}$} \\
\hline & $\begin{array}{l}16 \text { A } 25 \text { ANOS } \\
n=4(14.3 \%)\end{array}$ & & & $\begin{array}{c}\text { MAIS DE } 30 \text { ANOS } \\
\mathrm{n}=9(32.1 \%)\end{array}$ \\
\hline Modalidade & $\begin{array}{c}\text { BocclA } \\
\mathrm{n}=9(32.1 \%)\end{array}$ & $\begin{array}{c}\text { ATLETISMO } \\
\mathrm{n}=11(39.3 \%)\end{array}$ & $\begin{array}{c}\text { NATAÇÃO } \\
\mathrm{n}=7(25.0 \%)\end{array}$ & $\begin{array}{l}\text { EQUITAÇÃO } \\
n=1(3.6 \%)\end{array}$ \\
\hline $\begin{array}{l}\text { Tipo de } \\
\text { deficiência }\end{array}$ & $\begin{array}{c}\text { PARALISIA CEREBRAL } \\
n=11(39.3 \%)\end{array}$ & & & $\begin{array}{c}\text { MOTORA } \\
\mathrm{n}=8(28.6 \%)\end{array}$ \\
\hline
\end{tabular}

Quadro 2: Caracterização da amostra em função das variáveis anos de prática, número de anos de competição, número de internacionalizações, títulos conquistados e acompanhamento psicológico no desporto.

\section{Número de sujeitos}

$\mathrm{n}=28$

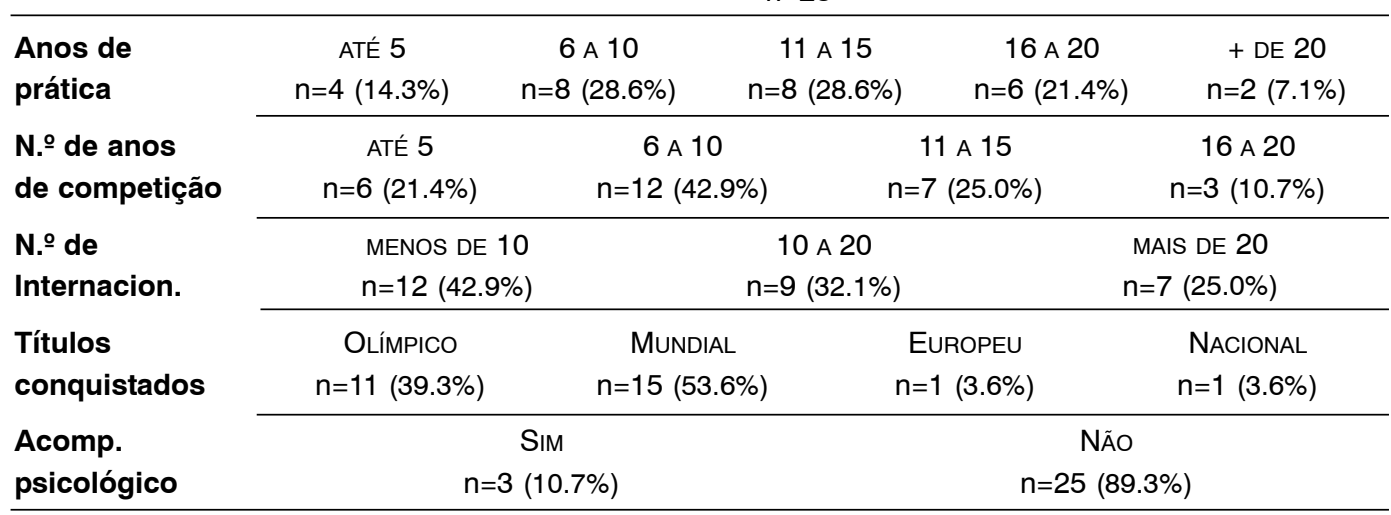


intervalo: (i) 0 a 19 - preparação mental fraca ou inexistente; (ii) 20 a 25 - preparação mental não sistemática; (iii) 26 a 30 - excelentes skills psicológicos representativos de uma preparação mental sistemática. Os atletas cujos valores se apresentem iguais ou superiores a $26 \mathrm{em}$ todos os parâmetros, revelam-se os mais consistentes nas suas prestações ${ }^{14}$.

Definiram-se como variáveis dependentes as sete dimensões do PPP. Como variáveis independentes, delimitaram-se as seguintes: (i) idade: 16-25, 26-30 e mais de 30 anos; (ii) sexo: masculino e feminino; (iii) tipo de deficiência: paralisia cerebral, deficiência visual e deficiência motora; (iv) modalidade praticada: boccia, atletismo, natação e equitação (esta dimensão não foi considerada na análise estatística comparativa, dado unicamente ser constituída por um indivíduo); (v) títulos conquistados (nível): olímpico, mundial, europeu e nacional (tendo em conta que apenas existia um sujeito de nível europeu e um de nível nacional, estes não foram considerados na análise estatística); e, (vi) acompanhamento por parte de um psicólogo do desporto: sim ou não.

\section{Estatística}

Inicialmente, recorremos à estatística descritiva no sentido de efectuar por um lado a caracterização da amostra, e por outro, verificar o score obtido por cada uma das variáveis (medidas de tendência central), para a partir daí ser possível identificar o nível de preparação psicológica dos atletas.

Posteriormente, procedemos à análise comparativa de acordo com os diferentes grupos definidos pelas variáveis independentes, utilizando o teste $\mathrm{t}$ de Student para amostras independentes quando comparámos dois grupos e a ANOVA one-way (teste post-hoc Scheffe) quando comparados três ou mais grupos. O programa utilizado foi o SPSS 12.0, considerando um nível de significância de $5 \%(\mathrm{p}<0.05)$.

\section{Resultados}

Os quadros seguintes apresentam os resultados em que se verificaram diferenças estatisticamente significativas.

Quadro 3: Análise descritiva e comparativa (Anova) por deficiência.

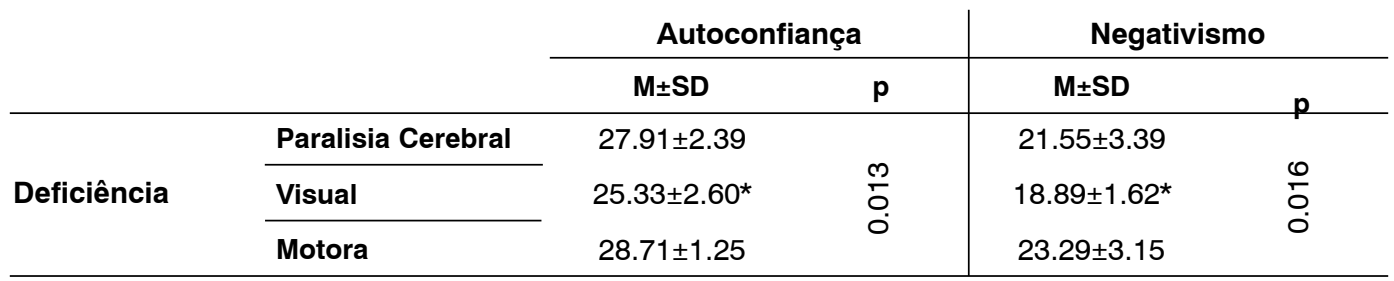

* Diferença significativa entre Visual e Motora $(p<0.05)$ no teste de Scheffé.

Quadro 4: Análise descritiva e comparativa (Anova) por modalidade e títulos conquistados.

\begin{tabular}{|c|c|c|c|c|c|c|c|c|c|}
\hline \multirow{2}{*}{\multicolumn{2}{|c|}{ 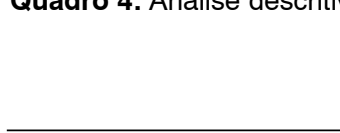 }} & \multicolumn{2}{|c|}{ Autoconfiança } & \multicolumn{2}{|c|}{ Motivação } & \multicolumn{2}{|c|}{ Visualização } & \multicolumn{2}{|c|}{$\begin{array}{c}\text { Atitude } \\
\text { Competitiva }\end{array}$} \\
\hline & & $\mathrm{M} \pm \mathrm{SD}$ & $\mathbf{p}$ & $\mathrm{M} \pm \mathrm{SD}$ & $\mathbf{p}$ & $\mathrm{M} \pm \mathrm{SD}$ & $\mathbf{p}$ & $\mathrm{M} \pm \mathrm{SD}$ & \\
\hline \multirow{3}{*}{ Modalidade } & Atletismo & $24.00 \pm 2.19$ & 0 & & & & & $24.55 \pm 2.30$ & \\
\hline & Boccia & $26.89 \pm 1.45^{\star} \ddagger$ & 8 & & & & & $27.78 \pm 1.72^{\star} \ddagger$ & $\mp$ \\
\hline & Natação & $23.57 \pm 2.94$ & 0 & & & & & $24.86 \pm 2.97$ & $\stackrel{\circ}{\circ}$ \\
\hline \multirow{2}{*}{ Títulos } & Olímpico & $23.55 \pm 2.42$ & $\hat{\varnothing}$ & $26.64 \pm 2.11$ & g & $21.27 \pm 4.56$ & ঙे & & \\
\hline & Mundial & $25.67 \pm 2.41$ & ○् & $28.20 \pm 1.74$ & $\stackrel{\circ}{\circ}$ & $24.73 \pm 3.28$ & ○’ & & \\
\hline
\end{tabular}

* Diferença significativa entre Boccia e Natação $(p<0.05)$ no teste de Scheffé.

‡ Diferença significativa entre Boccia e Atletismo $(p<0.05)$ no teste de Scheffé. 


\section{Discussão}

Quando considerada a análise dos resultados obtidos pela totalidade da amostra para cada uma das variáveis do Perfil Psicológico de Prestação, verificamos que os valores médios se situam dentro de dois intervalos distintos, correspondentes a dois diferentes níveis de preparação psicológica. Deste modo, de acordo com Loehr ${ }^{7}$, os atletas apresentam indicadores de preparação mental, contudo não sistemática, para os constructos atenção, negativismo, positivismo e visualização, tendo sido os valores obtidos nas restantes variáveis (autoconfiança, motivação e atitude competitiva) reveladores de excelentes skills psicológicos e representativos de uma preparação mental sistemática, ou, na nossa opinião, de uma experiência acumulada que lhes permite alcançar esses níveis. Tal assume-se pelo facto de somente três atletas serem acompanhados por psicólogos do desporto.

De acordo com os dados obtidos, verificámos serem as variáveis autoconfiança e motivação, aquelas que apresentam uma valorização média mais elevada, de entre as sete variáveis de estudo. Durand-Bush e Salmela ${ }^{2}$ encontraram resultados semelhantes quando pretenderam caracterizar e avaliar o desenvolvimento e manutenção da performance em 10 atletas de alto nível (campeões mundiais e olímpicos). De todas as características individuais de performance manifestadas, quatro delas distinguiram-se com os valores mais elevados, nomeadamente a autoconfiança e a motivação como sugerem os resultados do nosso estudo, sendo a criatividade e a perseverança, as restantes mais valorizadas.

O facto da motivação ter de todos o valor mais elevado, leva-nos por um lado, a considerar a existência de uma preparação mental mais consistente por parte dos intervenientes no estudo. Todavia, suscita também algum interesse pelo entendimento dos motivos que levam estes atletas a envolverem-se numa prática desportiva de alto nível. Em concordância com a perspectiva de Vasconcelos-Raposo ${ }^{16}$, que refere que a motivação tem necessidade de ser entendida como um conceito culturalmente relativista, em que os motivos para a participação desportiva diferem de indivíduo para indivíduo, consideramos este conceito particular no Desporto Adaptado, onde a prática desportiva constitui originalmente um veículo para a afirmação e demonstração de competência pessoal para o indivíduo portador de deficiência.

Comparativamente com outros estudos existentes no âmbito do Perfil Psicológico de Prestação e no que concerne à valorização média das variáveis dependentes, o nosso estudo apresenta valores mais elevados para todas elas à excepção da atenção, onde o estudo desenvolvido por Vasconcelos-Raposo ${ }^{15}$ apresenta um valor superior, e do negativismo, evidenciando-se o valor mais elevado para esta variável no estudo de Vasconcelos-Raposo e Carvalho ${ }^{17}$. Ao caracterizarmos o Perfil Psicológico de Prestação de atletas que apresentam comprometimentos físicos $\mathrm{e}$ alguns problemas sensório-motores graves ao nível dos orgãos receptores de informação, facilmente depreendemos que as capacidades atencionais e de concentração se apresentam à partida em patamares completamente distintos, independentemente do grau de desenvolvimento que as mesmas possam vir a atingir e dos indivíduos possuírem elevadas potencialidades, procurando constantemente a maximização das suas capacidades como atletas.

Considerando que os atletas do nosso estudo evidenciam níveis de autoconfiança bastante elevados, os valores apresentados no negativismo parecem sugerir apenas falta de preparação mental a este nível. Contudo, Vasconcelos-Raposo ${ }^{14}$ afirma que o negativismo está presente em todos os níveis do sistema desportivo nacional e deve-se ao facto dos treinadores serem muito relutantes quanto à utilização do feedback positivo. 
Alguns problemas inerentemente citados têm sido a falta de conhecimento técnico e científico respeitante à intervenção pedagógica ou uma preocupação exacerbada nos resultados da competição, menosprezando a qualidade da prestação. O controlo dos pensamentos negativos é definido como a capacidade de percepcionar situações difíceis como desafiadoras, em vez de problemáticas ou frustrantes. A importância que o treinador assume, refere-se ao feedback fornecido e como este é percebido pelo atleta. Por outro lado, o controlo dos pensamentos negativos e de dúvida por parte do atleta, deve-se proporcionar através da substituição de um pensamento negativo por um positivo, preferencialmente já percepcionado em competição, numa situação de relaxamento muscular. Como tal, o atleta deve evocar mentalmente ("mental recall') situações positivas e gratificantes, associadas a um diálogo interno ("self-talk") positivo.

Através da análise comparativa dos nossos resultados em função da variável sexo, verificamos para ambos os sexos, valores indicadores de excelentes skills psicológicos para as variáveis autoconfiança e motivação, sendo estes constructos mais valorizados pelo sexo feminino, apesar das diferenças não serem estatisticamente significativas. Denotamos contudo alguma contradição no facto do sexo masculino apresentar simultaneamente os valores mais elevados de negativismo e positivismo. Isto sugere que por um lado encaram a competição como ameaçadora, ao mesmo tempo que se consideram capazes e suficientemente competentes para obter sucesso na mesma.

Parecem estar presentes, neste sentido, para além de uma preparação psicológica insuficiente, factores de ordem sócio-cultural, sendo evidente uma maior pressão social sobre o sexo masculino, comparativamente a um nível de exigência social menos acentuado face às mulheres. Este facto é desencadeado por um processo de aculturação mais favorável ao homem em termos desportivos, o que lhe possibilita mais vivências desportivas e competitivas. Podemos ainda referir que o sexo masculino manifestou índices de atenção superiores em relação ao sexo feminino, tal como o estudo efectuado por Nideffer e Bond ${ }^{12}$. Ao analisarem os níveis de concentração em atletas de elite, os autores puderam concluir que os atletas do sexo masculino obtiveram valores percentualmente superiores aos manifestados pelo sexo feminino.

A partir dos resultados obtidos, não se verificaram diferenças significativas, quando comparados os indivíduos da amostra de acordo com as diferentes idades. Contudo, verificámos uma maior valorização de todos os constructos exceptuando a visualização pelos dois intervalos etários mais elevados, o que pode suportar a noção de que à medida que os atletas envelhecem, a sua preparação em termos psicológicos aumenta, sugerindo mais uma vez, a influência da experiência e da aprendizagem através da prática. Parece-nos importante salientar neste ponto, o facto das variáveis autoconfiança e motivação continuarem a evidenciar os valores mais elevados, sendo os valores, para ambas as variáveis, acima do $\operatorname{score}^{26}$ para todos os grupos de idades.

A motivação apresenta-se todavia com os valores superiores e mais idênticos para os três grupos de estudo definidos, situando-se entre os 27 e 28 valores. Este facto é corroborado pelo estudo efectuado por Durand-Bush e Salmela ${ }^{2}$, com o propósito de avaliar o desenvolvimento e manutenção da performance atlética em atletas de alto nível, numa amostra formada por 10 atletas (campeões do mundo e olímpicos). Nesse estudo, pese embora a estrutura de formação dos grupos etários utilizada não coincidir com aquela por nós definida, os valores mais elevados obtidos na variável motivação foram evidenciados por uma faixa etária que abarca os nossos três grupos de estudo. $O$ facto da valorização média da 
visualização ser superior no grupo etário mais baixo, leva-nos a salientar a importância desta estratégia de treino mental na aprendizagem de skills motores e a melhoria de performances desportivas, o que verifica-se preferencialmente nas idades mais jovens ${ }^{6}$.

Verificaram-se diferenças estatisticamente significativas, entre os grupos de deficiência motora e de deficiência visual para as variáveis autoconfiança e negativismo, sendo de referir que os atletas com deficiência motora evidenciaram valores médios superiores para ambas. Parece-nos também importante salientar o facto dos níveis de autoconfiança e atenção mais elevados terem sido revelados pelo grupo de deficiência motora, mostrando a primeira um valor médio no nível superior de preparação mental e a última se encontrar no extremo superior de uma preparação mental não sistemática (25 valores). De acordo com a literatura, existe uma forte ligação e interdependência entre estas duas variáveis.

De acordo com Nideffer ${ }^{11}$, situações de crise ou imprevistos como as que acontecem nos Jogos Olímpicos, são susceptíveis de provocar distracções múltiplas, o que exige que os atletas sejam capazes de redireccionar o seu foco atencional para a prestação e para o desafio competitivo o mais rapidamente possível após a sua ocorrência. Para o mesmo autor, em situações como a descrita, as consequências em termos atencionais, fisiológicos e de prestação dependerão dos níveis de autoconfiança do atleta. Quando estes são elevados a atenção permanece dirigida para os pontos relevantes da tarefa; quando estes são baixos o processo de recuperação é retardado e o foco atencional permanece dirigido para questões internas, o que pode implicar efeitos drásticos na performance.

No que respeita à paralisia cerebral, esta manifestou os índices mais baixos de atenção comparativamente aos dois restantes tipos de deficiência. De acordo com Marta ${ }^{9}$ a Paralisia Cerebral é acometida por problemas ao nível perceptivo-motor, dificuldades de aprendizagem e comunicação, e enormes défices atencionais. Desta premissa, podemos concluir que os baixos valores apresentados pelos atletas portadores de paralisia cerebral para a variável atenção, derivam de características inerentes à deficiência.

Os baixos índices de negativismo manifestados pelos atletas que apresentam deficiência visual, significativamente diferentes dos encontrados nos portadores de deficiência motora, poderão ser explicados exactamente pelo facto destes não possuírem uma capacidade perceptiva desenvolvida nos parâmetros normais. No decorrer dos eventos desportivos, o grande fluxo de informações erradas e passível de constituir um agente distráctil capaz de desencadear níveis indesejados de ansiedade competitiva e consequentemente de uma ocorrência (cascata) de pensamentos negativos, surge principalmente através daquilo que os nossos olhos observam, conjuntamente com todo um leque de estímulos e sensações associadas.

Da análise efectuada às diferentes modalidades paralímpicas, importa realçar que o boccia obteve os valores mais elevados em todas as variáveis, à excepção da atenção, denotando novamente níveis muito elevados de motivação e autoconfiança. De acordo com Ferreira ${ }^{3}$, um elevado autoconceito e uma elevada autoestima social neste tipo de população, está intimamente relacionado com o facto de desempenharem uma actividade profissional onde se sintam úteis, vejam reconhecido o seu valor e alcancem um sentimento elevado acerca de si mesmos. Apesar dos atletas desta modalidade possuírem limitações físicas muito acentuadas que não lhes permitem, na sua generalidade, desempenhar uma actividade profissional nos moldes socialmente impostos, estes assumem a prática da modalidade como a sua própria profissão, de onde advêm tais percepções.

Assim, a profissão por estes desempenhada (assumindo-se eles como atletas de alta competição) coincide com a actividade desportiva 
praticada, o que faz com que o prazer alcançado na actividade esteja aliado a um trabalho (treino) efectuado no mesmo sentido, resultando em elevados valores nos constructos em estudo. Os resultados do nosso estudo são idênticos aos encontrados por Gregório ${ }^{5}$, no qual os atletas praticantes de boccia, apesar de não possuírem qualquer actividade profissional, revelam valores igualmente elevados de auto-estima e auto-conceito. Os atletas de boccia possuem ainda os maiores índices de negativismo, pois são de todos os atletas, aqueles que possuem mais tempo intermédio para pensar, devido às características da modalidade. Este pressuposto está de acordo com Nideffer ${ }^{10}$, que caracterizou o negativismo como um comportamento que se manifesta sempre que um atleta tem muito tempo para pensar.

A partir dos resultados obtidos, constatou-se a existência de diferenças estatisticamente significativas, quando comparados os grupos de estudos em função dos títulos conquistados, tendo sido essas diferenças verificadas para as variáveis positivismo, motivação e visualização. No sentido de compreender as diferenças nas diversas variáveis, em relação aos títulos conquistados, comparámos os dados por nós obtidos com os encontrados por Gould e Dieffenbach ${ }^{4}$. Estes autores realizaram um estudo com o propósito de analisar as características psicológicas e o seu desenvolvimento em campeões olímpicos, sendo-lhes possível concluir que os atletas evidenciam um número de características psicológicas de elevado sucesso, bem como skills mentais diferenciados dos demais, que lhes permitem estados psicológicos óptimos.

Através da aplicação do teste das estratégias de performance (Test of Performance Strategies: TOPS - desenvolvido por Thomas et al., 1999), e da comparação dos valores da amostra olímpica com valores obtidos por o estudo de Thomas et al. ${ }^{13} \mathrm{com}$ atletas internacionais, os autores apresentaram resultados em tudo semelhantes aos obtidos no nosso estudo. Pese embora o
TOPS assente em sub-escalas de observação de comportamentos diferenciados, e os dados obtidos sejam traduzidos em intervalos numericamente mais baixos em relação ao Perfil Psicológico de Prestação, o estudo, tal como o nosso, apresentou valores mais elevados na variável atenção (por eles definida como controlo atencional) para os atletas olímpicos comparativamente aos internacionais, e valores mais baixos nas variáveis positivismo (self-talk positivo), negativismo (pensamentos negativos) e visualização (imagery) para este grupo comparativamente aos atletas internacionais.

Os resultados por nós apresentados permitem ainda inferir níveis motivacionais inferiores (e estatisticamente significativos) para os atletas olímpicos, comparativamente aos atletas mundiais. Um estudo elaborado por Mahoney, ao tentar identificar possíveis variáveis preditivas do alto rendimento desportivo na diferenciação de atletas de elite e não elite, evidenciou que os atletas de elite se mostravam significativamente mais motivados e com maiores índices de auto-estima.

Quando observámos os valores obtidos pelos atletas, para as variáveis do Perfil Psicológico de Prestação, tendo em consideração o facto de já terem tido ou não acompanhamento por parte de um psicólogo do desporto, verificámos de facto o esperado. Ou seja, que apesar de esse número de atletas ser bastante reduzido, eles obtêm valores consideravelmente superiores (apesar de estatisticamente não significativos), quando comparados com os demais atletas, exceptuando a variável negativismo, que obviamente se revela com níveis médios inferiores.

Deparamo-nos assim com uma evidência concreta, da elevada ajuda que pode ser prestada por parte destes técnicos na preparação mental dos atletas para a competição, podendo essa influência ser decisiva, a um nível competitivo onde pequenas diferenças no controlo mental e psicológico, podem constituir grandes diferenças em termos de performance, e determinar o grau de sucesso obtido pelos atletas, o que vem 
a corroborar a opinião de muitos treinadores, quando estes afirmam que as variáveis psicológicas são as que mais diferenciam os atletas de rendimento nos momentos das grandes competições.

Em suma, o presente estudo evidencia uma prevalência de valores consideravelmente elevados, para todas as variáveis que compõem o Perfil Psicológico de Prestação, o que vai ao encontro do proposto pela literatura, que indica que os atletas de elite se apresentam psicológica e mentalmente melhor preparados para a competição.

Contudo, a nossa observação dos resultados, leva-nos a considerar que estes não implicam necessariamente que os atletas sejam alvo de um treino mental sistemático, pelo que a experiência competitiva nos pareceu revelar-se um factor determinante nos valores demonstrados pelos atletas. E se é um facto que os nossos atletas revelam elevados níveis de prestação desportiva, também é verdade que essa poderia ser talvez ainda mais consistente e duradoura.

\section{Correspondência}

Ana Rita Bodas

Universidade de Trás-os-Montes e Alto Douro

Departamento de Desporto

Apartado 1013

5000 Vila Real, Portugal

E-mail: anarita@utad.pt 


\section{Referências}

1. Cruz, J. (1996). Psicologia do Desporto e da Actividade Física: natureza, história e desenvolvimento. In: Cruz, J. (Ed.) Manual de Psicologia do Desporto. Braga: Edições SHO.

2. Durand-Bush, N.; Salmela, J. (2002). The development and maintenance of expert athletic performance: Perceptions of World and Olympic champions. Journal of Applied Sport Psychology. 14: : 154-171.

3. Ferreira, L. (1998). Análise do Auto-conceito e da Auto-estima nos Indivíduos Portadores de Sequelas de Paralisia Cerebral. Dissertação de Mestrado. Porto: FCDEF-UP.

4. Gould, D.; Dieffenbach, K. (2002). Psychological characteristics and their development in Olympic champions. Journal of Applied Sport Psychology. 14: 172-204.

5. Gregório, A. (2002). Análise da Auto-estima nos Indivíduos Portadores de Sequelas de Paralisia Cerebral Praticantes de Boccia. Tese de Seminário. Lamego: ISPV.

6. Hall, C.; Giacobbi, P.; Hausenblas, H.; Fallon, E. (2003). Even more about exercise imagery: A grounded Theory of Exercise Imagery. Journal of Applied Sport Psychology. 15: 160-175.

7. Loehr, J. (1986). Mental Toughness training for Sports: Achieving atbletic excellence. Lexington: The Stephen Greene Press.

8. Mahoney, M. (1989). Psychological predictors of elite and non-elite performance in Olympic weightlifting. International Journal of Sport Psychology. 20: 1-12.

9. Marta, L. (1998). Boccia: Estudo-piloto sobre o estado de conbecimento na modalidade. Tese de Mestrado. Porto: FCDEF-UP.
10. Nideffer, R. (1985). Atbletes' guide to Mental Training. Champaign: Human Kinetics.

11. Nideffer, R. (1999). Concentration training for peak performance. [On-line]:

http://www.enhanced-performance.com/

12. Nideffer, R.; Bond, J. (2000). A cross-cultural examination of the concentration skills of elite level athletes. [On-line]:

http://www.enhanced-performance.com/

13. Thomas, P. R., Murphy, S. M., Hardy, L. (1999). Test of performance strategies: Development and preliminary validation of a comprehensive measure of athlete's psychological skills. Journal of Sports Sciences. 17: 697-711.

14. Vasconcelos-Raposo, J. (1993). Os factores psico-sócio-culturais que influenciam e determinam a busca da excelência pelos atletas da elite desportiva portuguesa. Tese de Doutoramento. Vila Real: UTAD.

15. Vasconcelos-Raposo, J. (1994). Perfil Psicológico de Prestação em futebol. Diferenças entre jogadores titulares e suplentes. Vila Real: UTAD.

16. Vasconcelos-Raposo, J. (2002). Motivação para a competição e treino: O caso das selecções portuguesas de natação. Estudos de Psicologia de Desporto. 1: 67-84.

17. Vasconcelos-Raposo, J.; Carvalho, F. (1998). Caracterização do Perfil Psicológico de Prestação do Jogador de Futebol nos diferentes Campeonatos Nacionais, $1^{a}$ Divisão, $2^{a}$ Divisão de Honra, $2^{a}$ Divisão $B e$ $3^{a}$ Divisão Nacional. Tese de Monografia. Vila Real: UTAD.

18. Weinberg, R.; Gould, D. (1995). Foundations of Sport and Exercise Psychology. Champaign: Human Kinetics. 